\title{
PERAN PUSTAKAWAN UPT PERPUSTAKAAN DALAM MENDUKUNG IKLIM RISET DI UNIVERSITAS ISLAM NEGERI ALAUDDIN MAKASSAR
}

\author{
Satriani ${ }^{1}$, Iskandar ${ }^{2}$, La Ode Ismail Ahmad ${ }^{3}$, Haruddin $^{4}$ \\ ${ }^{1}$ Mahasiswa Program S2 Jurusan Perpustakaan \& Informasi Islam, UIN Alauddin \\ Makassar \\ ${ }^{2}$ Dosen Program S2 Jurusan Perpustakaan \& Informasi Islam, UIN Alauddin Makassar \\ ${ }^{4}$ Pustakawan UPT Perpustakaan UIN Alauddin Makassar \\ Correspondence email: iswaninani@gmail.com
}

\begin{abstract}
The role of the library as research support (research) is becoming more of a concern in higher education. The main component that plays a role in library development is the librarian. Librarians as developers and maintainers of collections do not only serve to borrow and return books but librarians are required to be able to become liaisons or bridges of knowledge that is developing rapidly at this time. The method used in this study is a descriptive method with a qualitative approach. The data obtained from the study were described descriptively by making observations, then conducting interviews with librarians. The results of the study provide an overview of the role of librarians as educators (education and training), information managers, and administrators in supporting the research climate at UIN Alauddin Makassar.
\end{abstract}

Keywords: Librarian; Information Literacy; Research.

\begin{abstract}
Abstrak
Peran perpustakaan sebagai penunjang riset (penelitian) menjadi perhatian lebih di dalam Perguruan Tinggi Komponen utama yang berperan dalam pengembangan perpustakaan adalah pustakawan. Pustakawan sebagai pengembang dan pemelihara koleksi tidak hanya melayani peminjaman dan pengembalian buku, namun pustakawan dituntut untuk mampu menjadi penghubung atau jembatan ilmu pengetahuan yang berkembang pesat saat ini. Metode yang digunakan dalam penelitian ini adalah metode deskriptif dengan pendekatan kualitatif. Data yang diperoleh dari penelitian digambarkan secara deskriptif dengan melakukan observasi, kemudian melakukan wawancara kepada pustakawan. Adapun hasil penelitian memberikan gambaran peran pustakawan sebagai edukator (edukasi dan pelatihan), manajer informasi, dan admistrator dalam mendukung iklim riset di UIN Alauddin Makassar.
\end{abstract}

Kata Kunci: Pustakawan; Literasi Informasi; Riset. 


\section{A. Pendahuluan}

Perkembangan ilmu pengetahuan dan teknologi dimulai dari penelitian, percobaan, sistem induksi dan dedukasi untuk mengadakan analisis, sintesis dalam rangka merumuskan konsep-konsep penemuan baru. Perguruan tinggi sebagai wadah pembelajaran masyarakat, menjadi pusat pengembangan bangsa yang dituntut untuk selalu mengikuti perubahan dari proses pembelajaran yang harus berubah, produktivitas menulis harus bertambah, risetnya harus berkembang. Penelitian ilmiah dari berbagai disiplin ilmu civitas akademik sudah seharusnya menjadi budaya unggul. Kegiatan pembelajaran dan penelitian harusnya didukung oleh perpustakaan yang menyediakan sumber-sumber informasi yang lengkap dan dapat diakses dengan mudah.

Perpustakaan adalah lembaga ilmiah yang memberikan sumber untuk mengembangkan ilmu pengetahuan. Perpustakaan perguruan tinggi berperan sebagai jantungnya universitas dalam mendukung pelaksanaan Tri Dharma Perguruan Tinggi (Haryono and Cahyono 2020). Fungsi perpustakaan perguruan tinggi dalam Rancangan Peraturan Pemerintah tentang Pelaksanaan UU 43 tahun 2007 yaitu sebagai sumber belajar, penelitian, deposit internal, pelestarian, dan pusat jejaring bagi civitas akademik di lingkungan perguruan tinggi (Rahayu, Perpustakaan, and Ekonomi 2017). Peran perpustakaan sebagai penunjang riset (penelitian) menjadi perhatian lebih di dalam Perguruan Tinggi. Bagaimana pun perpustakaan perguruan tinggi harus menyajikan berbagai sumber informasi yang berhubungan dengan riset yang akan sedang atau sudah dilakukan. Dalam manajemen komunikasi, perpustakaan perguruan tinggi harus mampu memanfaatkan teknologi informasi sebagai sarana penunjang dalam penyebaran informasi dan membangun komunikasi ilmiah dengan penggunanya (Anawati 2019)

Potensi perpustakaan tentu perlu dikembangkan secara nyata agar berjalan sesuai kebutuhan zaman dengan melihat aktivitas seluruh sumber daya dalam menjalankan perpustakaan. Komponen utama yang berperan dalam pengembangan perpustakaan adalah pustakawan. Perpustakaan tidak akan berjalan dengan baik tanpa adanya seorang pustakawan. Maka perlu adanya pustakawan dalam aktivitas layanan perpustakaan. Pustakawan sebagai pengembang dan pemelihara koleksi tidak hanya melayani peminjaman dan pengembalian buku, namun pustakawan dituntut untuk mampu menjadi penghubung atau jembatan ilmu pengetahuan yang berkembang pesat saat ini. Mampu untuk mengadaptasi, memperkuat, dan menyesuaikan perannya dalam memberikan pelayanan kepada pemustaka. Pustakawan tidak hanya menjaga buku "book keeper" namun dari masa ke masa pustakawan bertransformasi sesuai dengan era informasi saat ini, dimana pustaka tidak hanya berupa buku akan tetapi telah berkembang dalam berbagai artikel jurnal ilmiah yang disediakan secara terbuka dan dapat diakses luas melalui internet.

Beberapa tahun terakhir ini, Universitas Islam Negeri Alauddin Makassar terus meningkatkan jumlah publikasi hasil-hasil penelitian dosen dan mahasiswa yang 
diterbitkan dalam jurnal nasional dan internasional. Tercatat sekitar 12,074 dokumen yang telah terakreditasi SINTA (Science and Technology Index) dan 15,979 dokumen yang telah dipublikasi di repositori UIN Alauddin Makassar, menunjukkan bahwa saat ini penelitian dan publikasi ilmiah mengalami peningkatan yang terus menerus meningkat dari tahun ke tahun. Namun terkadang dalam meneliti, dosen dan mahasiswa terkendala mencari referensi yang relevan dengan penelitiannya atau bahkan kesulitan menentukan judul yang akan mereka teliti. Untuk mendukung keberhasilan penelitian baik dosen dan mahasiswa ataupun seluruh sivitas akademik maka perlu dukungan dari pihak lain. Salah satunya adalah peran pustakawan dalam mendukung penelitian dan publikasi sivitas akademik.

Pustakawan yang dimaksud disini ialah bantuan yang diberikan oleh pustakawan dengan sungguh-sungguh guna mendukung riset sivitas akademik UIN Alauddin Makassar. Maka seorang pustakawan mesti menguasai profesinya khususnya kemampuan manajemen pengetahuan di era google saat ini. Tidak sekedar kumpulan pengetahuan yang dimiliki perpustakaan dimana pustakawan bekerja, namun juga pada pengetahuan-pengetahuan yang banyak tersaji di dunia virtual saat ini. Pustakawan dituntut memiliki kompetensi memadai dan professional dalam hal keterampilan, pengetahuan, pengalaman dan sikap kerja. Pustakawan yang peka terhadap kebutuhan informasi pemustaka, tidak hanya dalam kegiatan teknis dan layanan perpustakaan, namun juga dalam kegiatan riset.

Berdasarkan pemaparan tersebut diatas, tulisan ini bertujuan untuk mendeskripsikan peran pustakawan UPT perpustakaan dalam mendukung iklim riset di Universitas Islam Negeri Alauddin Makassar.

\section{B. Kajian Terdahulu}

Pustakawan yang bekerja pada lingkungan pendidikan tinggi sering disebut sebagai pustakawan akademik, yang menempatkan diri mereka berada tepat di tengah-tengah berbagai profesi khususnya pengajar dan peneliti. Peran pustakawan akademik cenderung lebih bergerak ke arah yang lebih strategis dan menantang terutama pada kegiatan riset. Diharapkan pustakawan akademik benar-benar "hadir, ada" untuk membantu menyelesaikan masalah pemustaka (sivitas akademik) dalam penemuan informasi ilmiah yang mereka perlukan untuk mendukung kegiatan penelitian mereka (Naibaho, 2018).

Salah satu peran strategis pustakawan akademik adalah sebagai mitra atau partner dalam kegiatan riset di perguruan tinggi. Penelitian yang dilakukan oleh Ulpah Andayani dalam tulisannya menemukan bahwa demi menjamin terselenggaranya kegiatan penelitian sivitas akademik, kontribusi pustakawan yang dapat dilakukan adalah sebagai konsultan riset (research consultant) untuk membantu peneliti dalam menemukan informasi yang diperlukan, serta membimbing mereka menggunakan perangkat teknologi dalam menelusur informasi. Memberikan pengajaran kemampuan riset (research skills) melalui program pendidikan literasi informasi bagi para sivitas akademik (Andayani 2016). Penelitian yang terkait juga dilakukan oleh 
Anis Kurniawati dan Ary Setyadi, menemukan beberapa kegiatan yang dilakukan pustakawan referensi untuk memberikan dukungan penelitian yakni dengan melakukan sosialisasi meliputi pengenalan fasilitas dan layanan perpustakaan serta mengenai informasi e-journal dan website perpustakaan. Kemudian melakukan pelatihan terkait pelatihan e-journal dan pelatihan mendeley serta pada pengolahan materi yang dilakukan pustakawan melalui repositori (Kurniawati and Setyadi 2019).

Seorang peneliti selain menggunakan sumber informasi berupa buku, juga memerlukan sumber informasi berupa jurnal ilmiah atau refereed journal untuk keperluan literature review. Peran pustakawan dalam penelitian dan publikasi dapat dilakukan dengan menyediakan sumber-sumber ilmiah baik dalam buku, jurnal ilmiah ataupun database joumal, pustakawan dapat memberikan bimbingan atau pendampingan kepada peneliti untuk membuat profil dalam akun google scholar sebagai sarana untuk publikasi agar dapat diketahui publikasinya secara mudah dan aktual. Kemudian peran lain yang dapat dilakukan pustakawan adalah dengan melakukan pemetaan tema dan subjek penelitian sehingga dapat membantu permasalahan peneliti dalam penentuan judul penelitian, terutama penelitian mahasiswa (Mustar 2017).

Pustakawan akademik dalam pendampingan menulis dan publikasi yang ditulis oleh Riah Wiratningsih mengeksplorasi kontribusi pustakawan dalam pendampingan proses menulis dan publikasi ilmiah di perguruan tinggi. Pustakawan sebagai mediator dan pendampingan mahasiswa dalam menulis ilmiah yang dipublikasikan dalam jurnal ataupun pada repositori perpustakaan. Pustakawan harus mahir dalam menelusur informasi menggunakan mesin pencari baik melalui google, repository perpustakaan, database e-book, e-journal, DOAJ, SINTA database index sitasi seperti scopus, scival, scimago, web of science, dan sebagainya (Wiratningsih 2020).

Dari beberapa kajian yang telah dipaparkan diatas menunjukkan bahwa pustakawan memiliki peran penting dalam mendukung kegiatan penelitian yang ada di perguruan tinggi. Bersamaan dengan perkembangan teknologi yang bertujuan untuk secara proaktif mendukung kegiatan penelitian dengan menyediakan sumber daya yang relevan, memperkuat proses penelitian, memfasilitasi komunikasi ilmiah dan mempromosikan hasil penelitian.

\section{Metodologi Penelitian}

Metode yang digunakan dalam penelitian ini adalah metode deskriptif dengan pendekatan kualitatif, dimana data yang diperoleh dari informasi dapat digambarkan secara deskriptif. Adapun data diperoleh melalui observasi, literarur yang relevan dengan peran pustakawan perpustakaan perguruan tinggi kemudian melakukan wawancara kepada pustakawan UPT perpustakaan UIN Alauddin Makassar. Dari hasil penelitian yang ditemukan diuraikan dalam deskriptif naratif (Sugiyono 2008).

\section{Hasil dan Pembahasan}

1. Sejarah Singkat UPT Perpustakaan UIN Alauddin Makassar 
Perpustakaan UIN Alauddin Makassar pada awalnya bernama perpustakaan IAIN Alauddin Makassar yang didirikan pada tanggal 10 November 1965 bersamaan dengan peresmian IAIN Alauddin Makassar Sesuai dengan surat menteri Agama Republik Indonesia 74 tentang berdirinya IAIN Makassar. Tenaga perpustakaan pada tahun 1965 sampai dengan tahun 1973 berjumlah dua orang yaitu kepala perpustakaan Bapak Syamsuddin dan satu staf Bapak Syahrir Aksa. Pada tahun 1975 perpustakaan mengalami kebakaran di akibatkan oleh arus listrik. Banyak koleksi yang ikut terbakar, sedangkan koleksi yang berhasil di selamatkan dipindahkan ke rumah jabatan rektor yang berada di lingkungan kampus.

Pada tahun 2009 perpustakaan melakukan transformasi bentuk layanan dari konvesional ke otomasi, yang ketika itu menggunakan ELiMS (Electronic Library Management System). Pada tahun 2011, lokasi perpustakaan pindah ke kampus 2 Samata Gowa, tepatnya di Jl. Sultan Alauddin No. 36 Romangpolong. Samata Gowa (sekarang Jl. H. M. Yasin Limpo) dan resmi disebut sebagai UPT (Unit Pelaksana Teknis) perpustakaan UIN Alauddin Makassar.

\section{Peran Pustakawan UPT Perpustakaan UIN Alauddin Makassar}

Menurut ODLIS (Online Dictionary Library and Information Science) "Librarian is A profesionally trained person responsible for the care of a library and its contents, including the selection, processing, and organization of materials and the delivery of information, instruction, and loan services to meet the needs of its users" (Reitz 2002). Pustakawan sebagai profesi yang bertanggung jawab mengurus perpustakaan dan isinya untuk kebutuhan penggunanya. Pustakawan atau librarian seperti yang tertulis dalam UU No. 43 Tahun 2007 tentang Perpustakaan yakni seorang yang mempunyai tanggung jawab terhadap perpustakaan dan telah memiliki pendidikan ilmu perpustakaan, baik melalui pelatihan, kursus, seminar, maupun dengan kegiatan sekolah formal.

Pustakawan sangatlah menentukan berfungsi tidaknya suatu perpustakaan. Sebagaimana diketahui bahwa pustakawan memberikan pelayanan informasi kepada pengguna perpustakaan (pemustaka). Profesionalisme pustakawan dalam setiap pekerjaannya saat ini sepenuhnya sangat dibutuhkan dengan pelayanan yang berprinsip pada people based service (berbasis pengguna) dan service excellence (layanan prima) yang hasilnya diharapkan dapat memenuhi kepuasan penggunanya (Mustika 2017). Peranan pustakawan berkembang dari waktu ke waktu, mereka tidak lagi hanya berfokus pada layanan sirkulasi buku tapi dituntut untuk dapat memberikan informasi secara cepat, tepat, akurat dan efesien dari waktu dan biaya.

Seorang pustakawan dikatakan sebagai informational professional yakni pengelola pengetahuan atau pengelola informasi dalam memahami dan memastikan kebutuhan informasi pemustakanya. Peran pustakawan dalam memberikan manfaat kepada masyarakat yaitu dengan memaksimalkan penggunaan sumber-sumber informasi. Artinya pustakawan memiliki kemampuan dalam bidangnya untuk membantu para pemustaka dalam menemukan koleksi atau informasi yang dibutuhkan. Maka kebutuhan pemustaka terpenuhi dengan adanya pustakawan yang paham akan 
sumber rujukan yang diinginkan pemustaka, paling tidak pustakawan mempertahankan peran mereka dalam lalu lintas informasi. Ini berarti bahwa pustakawan harus memiliki kualitas dan kompetensi dalam kinerjanya.

Menurut Rhoni Rodin kompetensi yang harus dimiliki pustakawan dalam mengelola informasi dengan baik yaitu pustakawan harus tahu di mana informasi tersebut berada dan bagaimana cara mengaksesnya sesuai kebutuhan pengguna (coleccting of information); pustakawan harus memiliki pengetahuan, keterampilan dalam memproses dan mengolah informasi agar mudah ditemukan kembali apabila dibutuhkan oleh pengguna (processing of information); pustakawan harus memiliki pengetahuan, keterampilan, sikap perilaku melaksanakan penelitian atau kajian pengguna agar mengetahui dan memperoleh gambaran yang jelas tentang karakteristik pengguna (disseminating of information). Profesionalisme dalam setiap pekerjaan pustakawan saat ini mutlak dibutuhkan, dengan memiliki cara kerja pelayanan yang berprinsip pada people based service (berbasis pengguna) dan service excellence (layanan prima) yang hasilnya diharapkan memenuhi kepuasan penggunanya (Rodin 2017).

The Canadian Association of Research Librarians (CARL) memberikan analisis yang berguna tentang 7 kompetensi akademik pustakawan yang diyakini dapat diterapkan di semua negara berteknologi maju yakni pengetahuan dasar (foundational knowledge), pengembangan koleksi (collections development), literasi informasi (information literacy), pengembangan profesional dan penelitian (professional development and research), keterampilan teknologi informasi (information technology skills), Keterampilan interpersonal (interpersonal skills), Kepemimpinan (leadership) (Hart and Kleinveldt 2011).

Iklim riset perguruan tinggi yang semakin meningkat menuntut tanggung jawab pustakawan untuk membuat perpustakaan menjadi sumber data pendukung penelitian. Salah satu peran dan tugas utama perpustakaan adalah mengembangkan information literacy (IL) skills seluruh sivitas akademik. Pengaruh yang dirasakan secara nyata dengan pengembangan skills ini adalah salah satunya pada peningkatan kualitas belajar-mengajar dan riset (Harliansyah 2016). Kemampuan yang harus dimiliki pustakawan dalam era digitalisasi yaitu kemampuan memahami dan menggunakan alat teknologi informasi (tool literacy), kemampuan memahami dan cara mendapatkan informasi (resource literacy), pemahaman terhadap informasi yang dihasilkan oleh berbagai pihak (social-structural literacy), kemampuan menggunakan peralatan berbasis teknologi informasi sebagai alat riset (research literacy), kemampuan menerbitkan informasi dan ide ilmiah dengan memanfaatkan komputer dan internet (publishing literacy), kemampuan dalam menyesuaikan diri dengan perkembangan teknologi (emerging technology literacy), dan kemampuan mengevaluasi dan memeriksa sumber informasi dalam kegiatan ilmiah (critical literacy) (Cahyadi 2018).

Tugas pustakawan akademik adalah melayani kegiatan akademis yang ada di UIN Alauddin Makassar terutama membantu dalam kegiatan penelitian. Sivitas akademik yang melakukan penelitian sangat beragam misalnya mahasiswa yang melakukan 
penelitian dalam bentuk skripsi atau tesis untuk memenuhi persyaratan lulus menjadi sarjana. Maka perpustakaan menjadi tempat tujuan utama peneliti dalam menemukan literatur yang sesuai dengan penelitiannya dan pustakawan menjadi pendamping peneliti dalam menelusur informasi yang relevan dengan penelitiannya. Peran penting pustakawan akademik tidak berubah yakni mempertemukan pencari informasi dan sumber informasi. Berikut ini hasil observasi dan wawancara beberapa peran umum pustakawan UPT perpustakaan UIN Alauddin Makassar dalam mendukung iklim riset.

\section{Sebagai Edukator}

Peran pustakawan sebagai edukator sangat penting di perpustakaan dimana pustakawan memberikan edukasi, bimbingan dan pelatihan kepada pemustaka untuk penelusuran informasi dari apa yang mereka ingin ketahui, apa yang ingin mereka pelajari dan peroleh. Maka dapat dikatakan bahwa dalam memberikan edukasi kepada pemustaka, seorang pustakawan harus mengetahui segala sumber-sumber informasi yang ada di perpustakaan dan sumber informasi lain secara komprehesif.

Pustakawan UPT perpustakaan mengadakan pendidikan pemustaka khususnya bagi mahasiswa baru untuk memperkenalkan perpustakaan dan memberikan materi atau presentasi terkait layanan, fasilitas, dan koleksi bahan pustaka. Bentuk lain dari pendidikan pemustaka adalah bimbingan pustakawan kepada pemustaka dalam menelusur berbagai sumber referensi yang ada di perpustakaan. Bimbingan dapat diberikan secara pribadi maupun kelompok bagi yang membutuhkan. Ini berguna untuk pemustaka atau peneliti dalam menelusur bahan pustaka secara mandiri nantinya. Pemustaka atau peneliti diarahkan bagaimana mencari buku di rak sesuai prodinya dengan menunjukkan nomor klasifikasi buku pada prodi masing-masing. Pustakawan memberikan pengajaran dengan menggunakan berbagai sumber informasi kepada civitas akademika.

Paham akan konsep serta sadar betapa pentingnya literasi informasi bagi pemustaka dan peneliti, sehingga pustakawan UPT perpustakaan melakukan kegiatan pelatihan akses kepada sivitas akademik agar penelusuran informasi menjadi lebih mudah. Literasi informasi mempunyai hubungan dengan kewajiban utama layanan perpustakaan. Cakupan pelayanan literasi informasi pada UPT perpustakaan UIN Alauddin ialah informasi mengenai proses mendapatkan serta menganalisis informasi. Adapun pelatihan akses yang diadakan oleh pustakawan UPT yaitu pelatihan e-journal, pelatihan mendeley, dan pengenalan google scholar.

Jenis kegiatan literasi informasi yang lain yang dilakukan oleh pustakawan UPT yaitu Workshop Digital Literacy "Penulisan Karya Tulis Ilmiah" untuk mendorong pemahaman mahasiswa dalam karya tulis dan menganalisa informasi yang ada. Juga sharing session yang merupakan bentuk rasa peduli pustakawan kepada tiap civitas akademik UIN Alauddin Makassar agar memahami bagaimana menghindari plagiasi untuk menghasilkan karya tulis ilmiah yang bermutu.

Sebagai Manajer 
Seorang manajer perpustakaan berwenang untuk merencanakan, mengorganisasi, mengatur, dan mengontrol dalam menyediakan kebutuhan informasi. Bertindak memilah bahan pustaka yang akan dikoleksi dan melakukan survey kebutuhan pemustaka. Pustakawan sebagai bagian dari knowladge management bertindak sebagai manajer ilmu pengetahuan harus mampu mengekstrak, menyaring dan menyebarluaskan pengetahuan. Pustakawan bertanggung jawab menjamin tersedianya berbagai koleksi bacaan referensi bagi para peneliti dalam melakukan penelitiannya. Membuat rancangan basis data untuk menyimpan, mengolah dan memperoleh kembali penelusuran informasi secara akurat.

Pustakawan UPT perpustakaan UIN Alauddin menerapkan sistem automasi dalam mengatur dan mengelola koleksi yang ada di perpustakaan. Program yang digunakan UPT perpustakaan adalah SLIMS (Senayan Library Management System) merupakan perangkat lunak yang didesain untuk memenuhi kebutuhan otomasi UPT perpusatakaan. Menyediakan layanan akses informasi yang dirancang dalam basis data yaitu repositori sebagai wadah untuk menyimpan dan mengolah karya ilmiah dalam bentuk digital yang dapat diakses secara luas. Penyediaan ruangan khusus penelitian bagi peneliti individu ataupun kelompok, agar peneliti bisa lebih fokus.

Pustakawan UPT perpustakaan tidak hanya saling bekerjasama antar pustakawan namun juga melibatkan pemustaka sebagai pemberi usulan pengadaan koleksi sampai pada usulan yang lain melalui kotak saran yang disediakan. Kemudian dari usulan pemustaka, pustakawan lebih leluasa menganalisis kebutuhan pengguna perpustakaan. Sehingga penyediaan berbagai macam koleksi dapat dilakukan secara tepat dan akurat.

\section{Sebagai Administrator}

Umumnya pelayanan administrasi kepada pengguna perpustakaan meliputi pendaftaran anggota perpustakaan dan peraturan tata tertib penyelenggaraan perpustakaan. Setiap pengguna harus didata kehadirannya untuk pengaturan pemanfaatan koleksi perpustakaan. Pustakawan mengelola daftar anggota dan pengunjung perpustakaan berdasarkan sistem yang telah ditentukan sehingga pengguna siap mendayagunakan koleksi yang ada. Sebagai administrator, pustakawan bertugas mengelola sumber-sumber informasi, menyediakan sarana penelusuran informasi, membantu dan terlibat langsung dalam pencarian informasi.

Pustakawan UPT melayani para peneliti mahasiswa ataupun dosen untuk mendapatkan sumber-sumber informasi dan referensi yang berkenaan dengan subjek penelitiannya. Membantu peneliti dalam penggunaan One search (katalog perpustakaan). Dengan layanan digital repositori di UPT perpustakaan memberikan wadah kepada dosen dan mahasiswa untuk mempublikasikan hasil penelitiannya ke dalam repositori dengan mengunggahnya secara mandiri atau meminta pustakawan untuk mengunggahnya.

\section{E. Kesimpulan}


Dari hasil penelitian diperoleh bahwa peran pustakawan UPT perpustakaan UIN Alauddin Makassar yaitu pertama sebagai edukator (pendidik) dimana pustakawan memberikan edukasi, bimbingan dan pelatihan penelusuran informasi. Kedua sebagai manajer dalam mengelola informasi dan menyediakan kebutuhan informasi peneliti. Ketiga sebagai administrator, memberikan wadah kepada peneliti untuk publikasi hasil karya ilmiah dosen dan mahasiswa.

\section{F. Daftar Pustaka}

Anawati, Sri. 2019. "OPTIMALISASI PERAN PERPUSTAKAAN SEBAGAI SARANA KOMUNIKASI ILMIAH: STUDI KASUS DI PERPUSTAKAAN UNIVERSITAS SEBELAS MARET SURAKARTA." BACA: JURNAL DOKUMENTASI DAN INFORMASI. doi: 10.14203/j.baca.v40i2.471.

Andayani, Ulpah. 2016. "Pustakawan Akademik Sebagai Mitra Riset Di Perguruan Tinggi.” AL-MAKTABAH 15(1):29-40.

Cahyadi, Dani Arif. 2018. "Kemampuan Literasi Informasi Peneliti Dalam Penulisan Karya Ilmiah Di Loka Litbangkes Pangandaran." Jurnal Kajian Informasi Dan Perpustakaan. doi: 10.24198/jkip.v6i2.17774.

Harliansyah, Faizuddin. 2016. "Peran Pustakawan Dan Perpustakaan Dalam Peningkatan Kualitas Perguruan Tinggi." in Kepemimpinan dan Profesionalisme Pustakawan: Kontribusi dalam Peningkatan kualitas perguruan tinggi.

Hart, Genevieve, and Lynn Kleinveldt. 2011. "The Role of an Academic Library in Research: Researchers' Perspectives at a South African University of Technology." South African Journal of Libraries and Information Science 77(1). doi: 10.7553/77-1-65.

Haryono, Bambang Santoso, and Teguh Yudi Cahyono. 2020. "IMPLEMENTASI KEBIJAKAN STANDAR NASIONAL PERPUSTAKAAN PERGURUAN TINGGI: DI PERPUSTAKAAN UNIVERSITAS NEGERI MALANG." BACA: JURNAL DOKUMENTASI DAN INFORMASI. doi: 10.14203/j.baca.v41i2.640.

Kurniawati, Anis, and Ari Setyadi. 2019. "Kontribusi Pustakawan Referensi UPT Perpustakaan Dalam Mendukung Penelitian Di Universitas Diponegoro.” Jurnal Ilmu Perpustakaan.

Mustar, Maniso. 2017. "Peran Pustakawan Dalam Penelitian Sebagai Upaya Meningkatkan Publikasi Ilmiah.” Media Informasi.

Mustika, Putera. 2017. "Profesionalisme Pustakawan.” Buletin Perpustakaan. 
Rahayu, Sri, Pustakawan Perpustakaan, and Fakultas Ekonomi. 2017. "Mengenal Perpustakaan Perguruan Tinggi Lebih Dekat." Buletin Perpustakaan 0(57):10310.

Reitz, Joan M. 2002. ODLIS: Online Dictionary Library and Information Science.

Rodin, Rhoni. 2017. Teknologi Informasi Dan Fungsi Kepustakawanan: Pemikiran Tentang Perpustakaan Dan Kepustakawanan Indonesia. Pertama. Yogyakarta: Calpulis.

Sugiyono. 2008. Metode Penelitian Pendidikan: Pendekatan Kualitatif, Kuantitatif, Dan R\&D. Bandung: Alfabeta.

Wiratningsih, Riah. 2020. PUSTAKAWAN AKADEMIK DALAM PENDAMPINGAN MENULIS DAN PUBLIKASI. Vol. 9. 